\title{
AN APPLICATION OF AUTO-IDENTIFICATION SYSTEM IN STEEL STRUCTURAL CONSTRUCTION PROCESS
}

\author{
Chun-Nen Huang', Doxon $\mathrm{Wu}^{2}$ and Ming-Teh Wang ${ }^{3}$ \\ ${ }^{1}$ Ph.D., Associate Research Fellow, Taiwan Construction Research Institute, chun-neh@tcri.org.tw \\ ${ }^{2}$ Ph.D., Associate Research Fellow, Taiwan Construction Research Institute \\ ${ }^{3}$ Ph.D., President, Taiwan Construction Research Institute
}

\begin{abstract}
Being an integral part of accessing the modern automated system, Auto-ID (Automatic Identification) system is a proven technology of providing a more accurate, detailed, timely and advanced information for architectural operation. Currently, the various technologies that are used for Auto-ID are: barcodes, optical character recognition (OCR), radio frequency identification (RFID), magnetic stripe and voice recognition. The focus of this study is mainly on the interface integration of Auto-ID system, including barcode, radio frequency, wireless technology and database systems etc. Among the diversified expert fields in the construction industry, the methodologies used for site-casting and pre-casting steel structure are very similar to that of manufacturing industry. By setting up suitable Auto-ID system module for construction environment and taking actual steel structure construction case as an example, a preliminary prototype has been developed in this study. After the prototype is thoroughly analyzed, guidelines that aim at effectively initiate the utilization of this Auto-ID system is formulated and ideas for further research are recommended.
\end{abstract}

Keywords: Aut-ID, Bar Code, and Steel Structural Construction Process

\section{INTRODUCTION}

This study focuses on interface integration of bar code system, including the bar code system, wireless technology and database system etc., so as to set an Auto-ID system module for construction environment. Furthermore, a practical steel structure construction is established as a case study herein to propose a primary module for Auto-ID system.

Within the various fields of construction industry, steel structural engineering is very similar to manufacturing industry in terms of its material and manufacturing processes, as well as manufacturing application, indicating that Auto-ID system can also be applied in the practical operation of steel structural engineering. While Bar Code Auto-ID system has already been collaborated with the function of Data Base sytem, and together with the wireless transmission of information, the application of this mechanism to steel structural engineering should be very feasible.

\section{SYSTEM ARCHITECTURAL DESIGN AND ANALYSIS}

Auto-ID system can be directed into various procedures of construction material and production processes, such as production planning, product design, manufacturing, material transportation, on-site storage and installation etc., [1] so as to reach the purposes of installation consistency and standardization, paperless and unmanned conditions, and also considerably reduces human data entry errors and time required. Subsequently, it is hoped that both the productivity and economic efficiency of the construction can be improved. Based on this concept, this paper suggested that project such as "high-raise story steel structural building," which requires repetitive construction methods and consistent steel parts, is very suitable in incorporating with Bar Code Auto-ID System. The life cycle of steel structure building project can be viewed as an integrative process. Based on its operational characteristics and special requirement, appropriate concept of Bar Code ID system is adopted and applied to the most feasible scope in times of the building construction. Figure 1 . indicates a preliminary simulative system that is established herein for meeting the requirement of engineering automation. The so-called life cycle of steel structural building projects covers the areas of steel structural planning, structural part design, manufacturing and storage, transportation and erection of parts, and on-site temporary storage. Also, this concerns the total processes of practical erection and installation, including the treatment of fundamental parts such as column and beams as an object, whereas the dimension, weight, steel type, connection method, placement in the building, storage area, transportation sequence and erection order etc. of its similar columns and beams are all treated as behavioral objects. By so doing, the behavioral parts having the same nature can be inherited and attributed completely. Through the "Read" function of Bar Code Identification, full 
automation can be achieved towards the OODBS (Object Oriented Data Base), which is a type of data base management module that has widely been promoted in IT industry within the past few years.

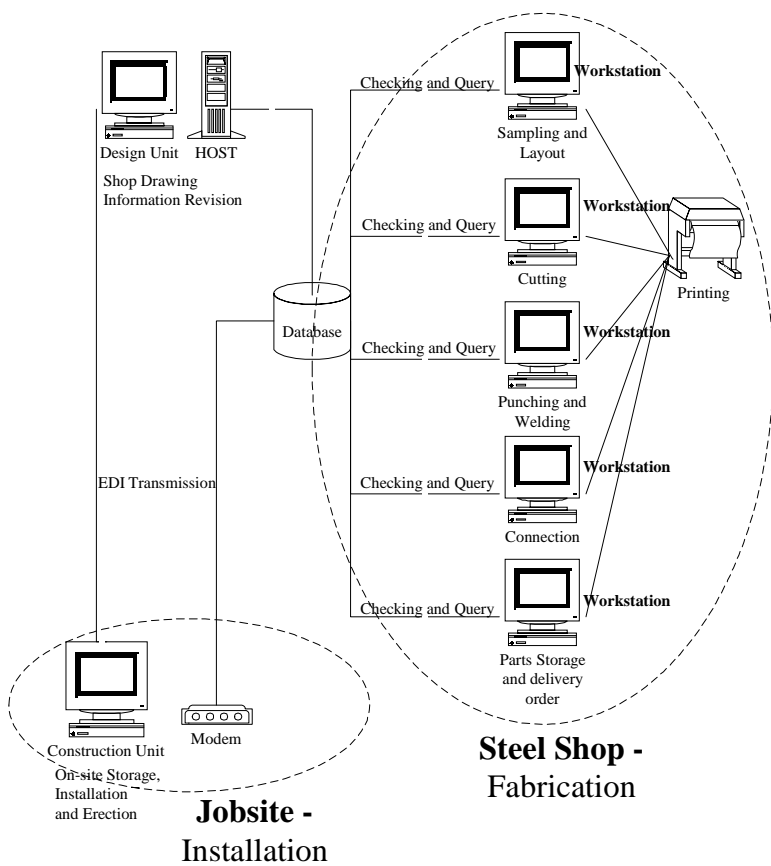

Fig 1. A Preliminary Simulative System for Steel Construction Work Flow

\subsection{Workflow of Steel Structural Engineering}

The above section illustrates a brief workflow adopted in traditional steel structural engineering. It is expected that by implementing a better data processing method, its overall efficiency can be optimized. Table 1 demonstrates the critical management items and Auto-ID design requirement for a typical steel structural building.

(1) Design and Planning Stage (Pre-production Stage): In this stage, an integrative coding process can be accomplished based on the design materials, such as guideline and drawings etc., of the columns and beams. Coding every part is very necessary in building the bar code system, in which the attributes of the parts, such as dimension, weight, steel type, connection method, placement different story of the columns and beams have to be considered, built and saved in the Data Base System.

(2) Factory Manufacturing Stage: In this stage, through various mechanisms that are established in the design planning stage, namely, data base submittal and document, shop drawing files and computing technology such as Intranet and Internet configured within an organization, documents and information of the engineering can be digitalized for real time enquiry and mutual transmission. By so doing, manual processing can be greatly reduced, while increasing the transmission speed, and maintaining the accuracy of the recorded information. Upon completion of manufacturing the parts, bar code identification towards the coding of parts, which has been the outcome of the previous step, is immediately executed. Respective bar code is labeled on the areas of parts which are more visible and not easy to wear off. At present, iron or copper-casted bar codes are available for job site where the parts are prone to wear and tear.

(3) On-site Erection Stage: By means of bar code and Auto-ID function, problems of partitioning and stacking order, such as parts transportation (i.e., transporting the parts from the factory to job site in the right stacking order), on-site temporary storage, and erection etc. can be solved, so as to considerably reduce manual identification time and human identification errors, prevent labor and machinery idling and subsequently lead to the increase of production and economic efficiency.

Table 1. Critical Management Items and Auto-ID Design Requirement of Steel Structural Building

\begin{tabular}{|c|c|c|c|}
\hline Procedure & Item & Requirement & $\begin{array}{l}\text { Automation } \\
\text { Requirement }\end{array}$ \\
\hline \multirow[t]{2}{*}{ Production } & $\begin{array}{l}\text { Assessment of } \\
\text { design } \\
\text { drawing } \\
\text { standard }\end{array}$ & $\begin{array}{l}\text { Queries and } \\
\text { clarification of } \\
\text { errors and } \\
\text { inconsistency }\end{array}$ & $\begin{array}{l}\text { Establishment of } \\
\text { coding system }\end{array}$ \\
\hline & $\begin{array}{l}\text { Writing and } \\
\text { editing of } \\
\text { construction } \\
\text { planning } \\
\text { proposal and } \\
\text { drawings }\end{array}$ & $\begin{array}{l}\text { Meeting the } \\
\text { quality } \\
\text { requirement of } \\
\text { design/supervise } \\
\text {-ory units }\end{array}$ & $\begin{array}{l}\text { Establishment } \\
\text { of data base } \\
\text { system }\end{array}$ \\
\hline Preparation & & & $\begin{array}{l}\text { Establishment } \\
\text { of document } \\
\text { and graphic } \\
\text { folders } \\
\text { Establishment } \\
\text { of EDI }\end{array}$ \\
\hline \multirow[t]{2}{*}{ Factory } & $\begin{array}{l}\text { Material } \\
\text { in-factory } \\
\text { management }\end{array}$ & $\begin{array}{l}\text { Meeting the } \\
\text { quality } \\
\text { requirement }\end{array}$ & $\begin{array}{l}\text { EDI feedback } \\
\text { transmission }\end{array}$ \\
\hline & $\begin{array}{l}\text { Welding } \\
\text { process }\end{array}$ & $\begin{array}{l}\text { Meeting the } \\
\text { requirement of } \\
\text { construction } \\
\text { process proposal }\end{array}$ & $\begin{array}{l}\text { Convert the } \\
\text { coding into bar } \\
\text { code Auto-ID } \\
\text { system }\end{array}$ \\
\hline $\begin{array}{c}\text { Manufactu } \\
\text { ring }\end{array}$ & $\begin{array}{l}\text { Dimensional } \\
\text { precision of } \\
\text { the completed } \\
\text { parts }\end{array}$ & $\begin{array}{l}\text { Proper usage of } \\
\text { processing and } \\
\text { assembling } \\
\text { equipment }\end{array}$ & \\
\hline
\end{tabular}

\footnotetext{
${ }^{1}$ EDI: Electronic Data Interchange
} 


\begin{tabular}{c|l|l|l}
\hline On-site & $\begin{array}{l}\text { Bolt } \\
\text { anchoring } \\
\text { process }\end{array}$ & $\begin{array}{l}\text { Meeting the } \\
\text { requirement of } \\
\text { construction } \\
\text { process } \\
\text { proposal. }\end{array}$ & $\begin{array}{l}\text { Auto-ID system } \\
\text { operation and } \\
\text { storage }\end{array}$ \\
\cline { 2 - 4 } $\begin{array}{l}\text { Precision of } \\
\text { erection and } \\
\text { assembling }\end{array}$ & $\begin{array}{l}\text { Meeting the } \\
\text { requirement of } \\
\text { construction } \\
\text { process } \\
\text { proposal. }\end{array}$ & $\begin{array}{l}\text { Erection and } \\
\text { installation of } \\
\text { Auto-ID system }\end{array}$ \\
\hline Erection & $\begin{array}{l}\text { On-site } \\
\text { welding } \\
\text { process }\end{array}$ & $\begin{array}{l}\text { Meeting the } \\
\text { requirement of } \\
\text { construction } \\
\text { process } \\
\text { proposal. }\end{array}$ & $\begin{array}{l}\text { Checking and } \\
\text { recording } \\
\text { feedback }\end{array}$ \\
\hline
\end{tabular}

\subsection{Establishing the Data Base System}

Viewing parts as objects, categorize those sharing the same attributes, such as size and weight etc., into the same group. Next, analyze into the structural information (such as storage area of the parts, layers and production sequencing) and then plan for the construction process accordingly.

\subsection{Establishment of a Search Hub-Basic Concept}

Based on the design standard and detailed drawing of the construction, search hubs are established at the major stations controlling and tracking the engineering process by means of bar code. Also, with appropriate setting of checklist, it is possible to examine whether the quality of every part can comply with the ideal design standard and drawing. As a result, quality inspection can be undergone before every part leaves the factory.

\section{BENEFITS OF ADOPTING AUTO-ID IN STEEL STRUCTURAL ENGINEERING}

\subsection{No Need to Identify the Steel Parts by Manual Labor}

Traditionally, when steel parts are produced and ready for shipment, they are painted with dominant marks, showing their on-site placement position such as North, South, East, West (or A, B, C and D), as well as other information such as serial number, weight, and numbers of sections etc., so as to optimize the storage process. However, if Bar Code System is adopted and the prepared bar codes (which can be produced by either iron casting or plating confronting the wear and tear problem in the job site, ) are labeled on them before leaving the factory, their identity can then be read directly by a portable decoder. Subsequently, manual labor can vastly be saved, and possible errors in identifying the parts can be reduced [2].

\section{and Documents}

Traditionally, before the steel structural parts are sent to the job site, manufacturer has to prepare complete processing and quality control documents of their products (such as quality control chart, inspection chart, process control sheet and checklist etc.), so that the site workers would fully understand the specification of these parts [3]. When the parts have reached the on-site temporary storage area, operators still need to undergo paper works for an effective erection procedure. However, if bar code system is implemented, manufacturers can use EDI to maintain the quality control documents, and acquire basic information of the parts, such as size, weight, serial number, numbers of sections and storage area etc. They can then transmit these data to the site operators, preventing them from repetitive data entry. Instead, they are required to identify the parts with bar code, and then extract related information from the database. This method can improve the job performance and accuracy of the total process.

\subsection{Enhance Productivity}

Another selling point of automation is the improvement of productivity. With today's labor shortage and labor and material cost increase, automation is an unavoidable trend in all sorts of industries, ensuring industrial upgrade and increase competitiveness in the international scene. Introduction of bar code Auto-ID system and EDI into construction industry are exactly the means to leverage the potential of automation.

\section{SYSTEM HARDWARE AND SOFTWARE}

\subsection{System Hardware Structure}

This system comprises of bar code automatic identification and wireless data transmission functions. In this section, the hardware system configured in the research thesis is introduced, wherein the main devices are all provided by Intermec Company [4 \& 5], including the construction use bar code scanner, construction use portable wireless transceiver and construction use wireless digital adapter, as well as special hardware devices such as construction use wireless digital network controller etc. All these devices perform the functions of data entry, decode, transmission, control interface, and storage etc. Detailed description of these system devices is as follows.

Figure 2 shows the system hardware structure, wherein the processing of this set of hardware devices starts at Intermec 9465, the data collector. 
This collector receives data from the on-site bar code, which then transmits data by means of spread-spectrum wireless frequency. Also, it receives data acquired by bar code via Intermec 9181 main data transceiver, and then send it back to host computer for further processing [6].

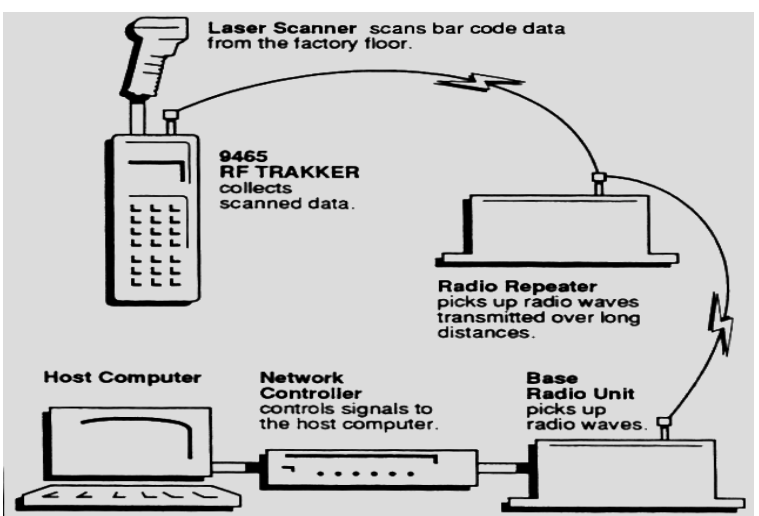

Figure 2. System Hardware Structure

\subsection{Bar Code Laser Scanner}

As shown in Figure 3, the Bar Code Laser Scanner is developed by Intermec Company, having the product serial number of KB1565A01 (or simply 1565). This scanner scans bar code directly by means of laser visible, and then immediately displays the decoded bar code on its digital monitor (Vacuum Fluorescent Display having 4 lines of 20 characters). Its accessory of a small keypad carries multiple scanning functions, including scanner, display and keypad. Also, this scanner can decode bar code of different format and mode (including UPC/EAN, Code 39, Codabar, 2 of 5, Code 11, Code 93, Code 128 and UCC128.)

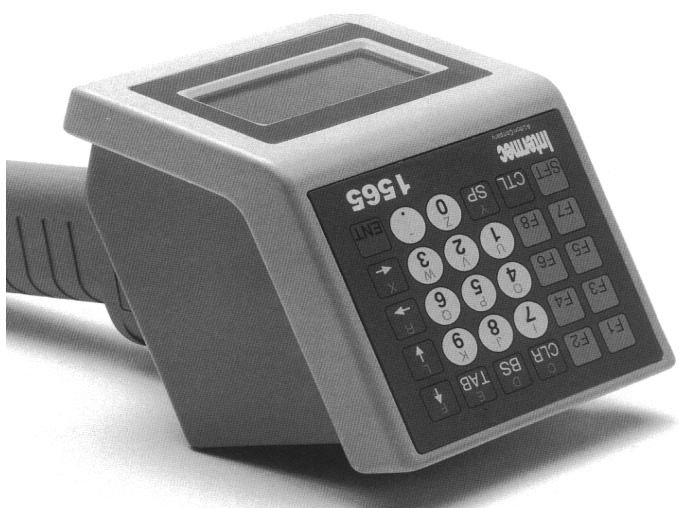

Figure 3. Bar Code Laser Scanner

Portable Wireless Transceiver, product serial number being 9465A02010 (or simply 9465), is also known as Collector in Real-time developed by Intermec Company. This RF Transceiver can transmit two-way interactive data through spread-spectrum radio frequency, allowing both manual data entry (keyboard containing 48 keys) and connected bar code scanner (1565) data transmission. Its internal is interpreted and edited by Interactive Reader Language (IRL), which is also developed by Intermec Company, providing program designer the necessary tools for program development and utilization.

Developed by Intermec Company, Wireless Digital Network Controller is also known as Network Controller, and its product serial number is KB9180 (or simply 9180). As shown in Figure 4, this device mainly supports the wireless transceiver and the network control of wireless digital adapter, which is used for connecting Host Computer, processing the asynchronous communication. It can also support data transmission to 128 sets of wireless transceiver (9465) at the same time.

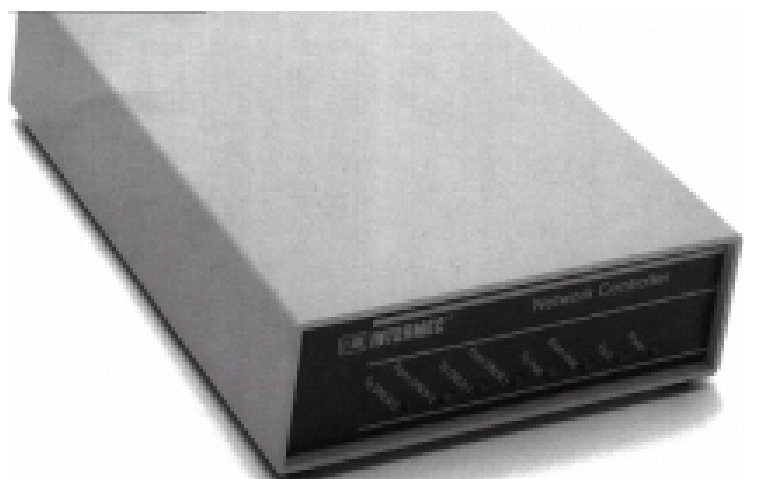

Figure 4. Wireless Digital Network Controller -Network Transceiver

\subsection{System Software}

The system software includes: document processing software of Microsoft Word, graphics treatment software of VISIO 5.0, IRL bar code interpretation and editing programming language which is developed by Intermec Company, and Intrscan operation environment system software. Also, the bar code labeling and editing software of LBCC 2.5 is adopted. All these software are performed under the operation system of FOXPRO for Windows carrying multimedia data base function.

This system selects Microsoft Windows Chinese Version to be the operation environment of the system. The main reasons being: Windows carries the properties of "object-oriented" as well as the functions such as DLL (Dynamic Link Library), OLE (Object Linking And Embedding) and DDE(Dynamic Data Exchange) etc., so that the applications being executed under Windows can easily deliver and exchange data between each other without the limitation of $640 \mathrm{~K}$ memory. Besides, some unique functions such as GUI (Graphical User Interface), DIG (Device Independent Graphics), Device Independent Graphics and MDI (Multiple Document Interface) have enabled Windows to be the best PC's operation environment to develop and 
create multi-media system.

\section{INPUT, OUTPUT AND FUNCTION DESIGN OF THE SYSTEM SCREEN}

The major function of the system is to provide users with detailed content search of the steel parts. Through the multi-functional data base screen builder of FOXPRO 4GL, the configuration of the system screen is as simple as to place different interface objects on the displayed panel, so as to build the graphics style, as well as the complicate data entry screen format. The screen designed by the system is used to describe the integration of Auto-ID system. Together with wireless technology and the fourth generation data base languages, it is applied on the primary module constructed by the steel structural construction engineering.

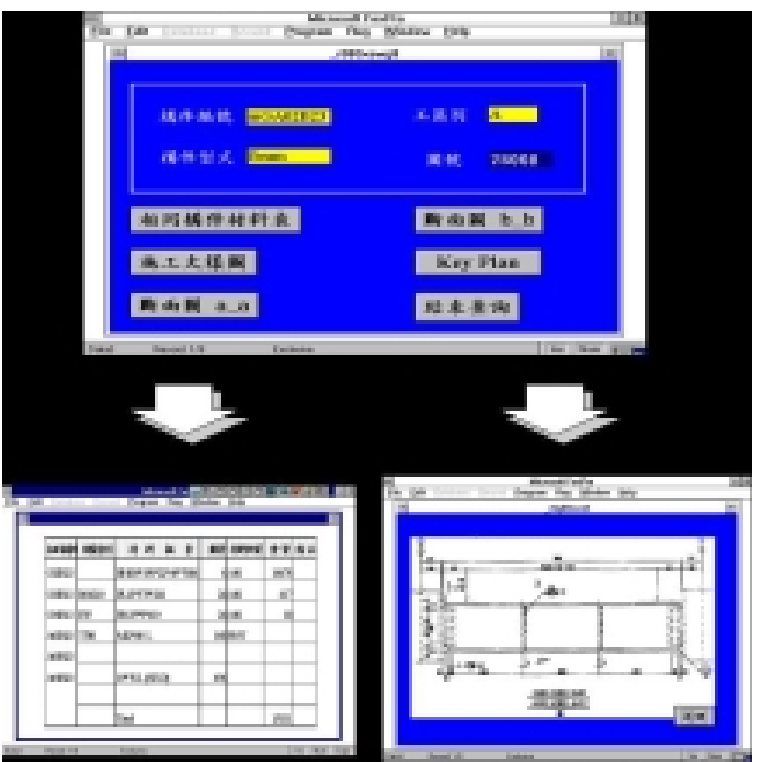

Figure 5. Screen Desing-1

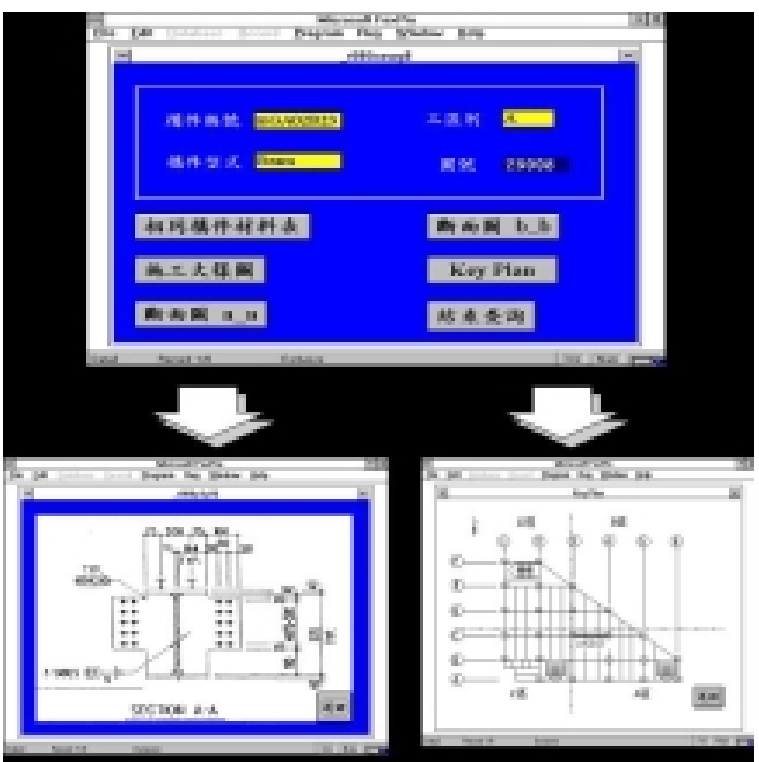

Figure 6. Screen Desing-2

\section{CONCLUSIONS}

The following findings can be drawn as the conclusion of this application:

(1) Integration of Auto-ID system can greatly improve productivity.

The ultimate purpose of single data base concept is to achieve the automation of integrative engineering, wherein Auto-ID system is indispensable in its configuration. From the information collected in this research, it is known that with the collaboration of other technology, such as EDI, CAD, Robot, Expert System and Multi-media etc., it can greatly improve the productivity of construction.

(2) Collaboration of Auto-ID System based on the characteristics of construction industry.

Because of its complicate and changeable characteristics, construction industry varies greatly from most commercial and industrial business. As a result, successful commercial, industrial or other business-related case studies may not be fully applicable to this specific area. Emphasis should be placed on analyzing and assessing its unique nature, so as to optimize the processing performance.

(3) Cost efficiency of whole system should be fully considered.

Nowadays, Auto-ID system is a very sophisticated technology, which is vastly applied in different scopes, such as material management, tracking of labor affairs, financing and equipment management and document control etc. However, upon considering the adoption of this new technology, decision makers always consider the incurred cost while overlooking the performance that this technology can bring forth. For example, Auto-ID system can provide real time, historical and comparative processing, enabling a quick and accurate decision-making. Currently, popular known as RFID can serve either as AUTO-ID or auto data collection system. Regardless of its role, the new system should collaborate with management tools that are commonly used in construction industry (such as budget estimation, construction status control, cost control, performance evaluation, and S-Curve etc.), so as to achieve its management functions. The issue of integrating these technologies and management tools should be set as the research direction in the future.

\section{REFERENCES}

[1] Harry E.Burke, “ Handbook of Bar Coding systems”, Data Pathing Systems Division NCR Corporation 1984. 
[2] Rasdorf, William J. and Herbert, Mark J. "Bar Coding in Construction Engineering." Journal of Construction Engineering and Management, ASCE, Vol.116, No.2, pp. 261-279, 1990.

[3] Bernold, L.E., "Bar Code-Driven Equipment and Materials Tracking for Construction", Journal of Construction Engineering and Management, ASCE, Vol 118, No. 4, pp. 381-395, 1990.

[4] Intermec. (1) "Understanding Radio Frequency Data Collection." Business Brochure, Intermec Corporation, Everette, 1991.

[5].Intermec. (2) "The Evaluation of Automated Data Collection." Business Brochure, Intermec Corporation, Everette, 1991.

[6] Intermec Corporation, "How to evaluate an investment for automated data collection”, 1989.

[7].Bernold, L.E., "Bar Code-Driven Equipment and Materials Tracking for Construction", Journal of Construction Engineering and Management, ASCE, Vol 118, No. 4, pp. 381-395, 1990. 